\title{
Bromine counts from XRF scanning as an estimate of the marine organic carbon content of sediment cores
}

\author{
Martin Ziegler, Tom Jilbert, Gert J. de Lange, Lucas J. Lourens, and Gert-Jan Reichart \\ Department of Earth Sciences, Utrecht University, Budapestlaan 4, Utrecht, Netherlands (ziegler@geo.uu.nl; \\ jilbert@geo.uu.nl)
}

[1] XRF sediment core scanning technology is increasingly used to quantify sediment composition. The overall good correlation between biophilic halogen bromine $(\mathrm{Br})$ and sedimentary total organic carbon (TOC) potentially allows the fast estimation of down core TOC profiles by XRF scanning. In order to test this approach we present data from the Arabian Sea and a Mediterranean brine basin, comparing XRF core scanning $\mathrm{Br}$ data with discrete sample TOC analyses. Overall, Br counts and TOC show a clear correlation, except when stable carbon isotope and $\mathrm{C} / \mathrm{N}$ data indicate intervals characterized by enhanced input of terrestrial organic matter. Hence, solid phase $\mathrm{Br}$ is exclusively associated with marine organic matter (MOC) and can be used as a direct estimate of this parameter after a calibration is established. High pore water $\mathrm{Br}$ in the brine core steepens the $\mathrm{Br} / \mathrm{TOC}$ correlation but after salt correction shows a nearly identical gradient to that of the Arabian Sea core.

Components: 3189 words, 3 figures.

Keywords: X-ray fluorescence; XRF core scanner; sediment chemistry; bromine; sedimentary organic carbon.

Index Terms: 1051 Geochemistry: Sedimentary geochemistry; 3094 Marine Geology and Geophysics: Instruments and techniques; 3036 Marine Geology and Geophysics: Ocean drilling.

Received 20 December 2007; Revised 11 February 2008; Accepted 24 March 2008; Published 15 May 2008.

Ziegler, M., T. Jilbert, G. J. de Lange, L. J. Lourens, and G.-J. Reichart (2008), Bromine counts from XRF scanning as an estimate of the marine organic carbon content of sediment cores, Geochem. Geophys. Geosyst., 9, Q05009, doi:10.1029/2007GC001932.

\section{Introduction}

[2] Recent advances in XRF sediment core scanning technology [Richter et al., 2006; Thomson et al., 2006; Tjallingii et al., 2007] have paved the way for the use of elemental counts as tracers of variability in less readily quantified sediment constituents. Profiles of sedimentary total organic carbon (TOC) and marine organic carbon (MOC) are widely used in reconstructions of the balance between sea surface productivity and preservation in a range of oceanic environments [Rühlemann et al., 1999], notably the Arabian Sea [Reichart et al., 1998; Schulz et al., 1998] and Mediterranean [Rohling, 1994, and references therein]. The origin (marine or terrestrial) of organic matter in sediments is furthermore an important parameter in global carbon budget calculations. However, existing procedures to establish down core TOC profiles, and to differentiate between the two sources (e.g., $\delta^{13} \mathrm{C}$, TOC: $\mathrm{N}_{\text {total }}$, or the newly developed biomarker-based Branched and Isoprenoid Tetraether (BIT) index [Hopmans et al., 2004]), require the analysis of discrete sample series. Sedimentary $\mathrm{Br} / \mathrm{TOC}$ can be employed as an alternative tracer for marine versus terrestrial organic carbon [Mayer et al., 2007], using the principle that 

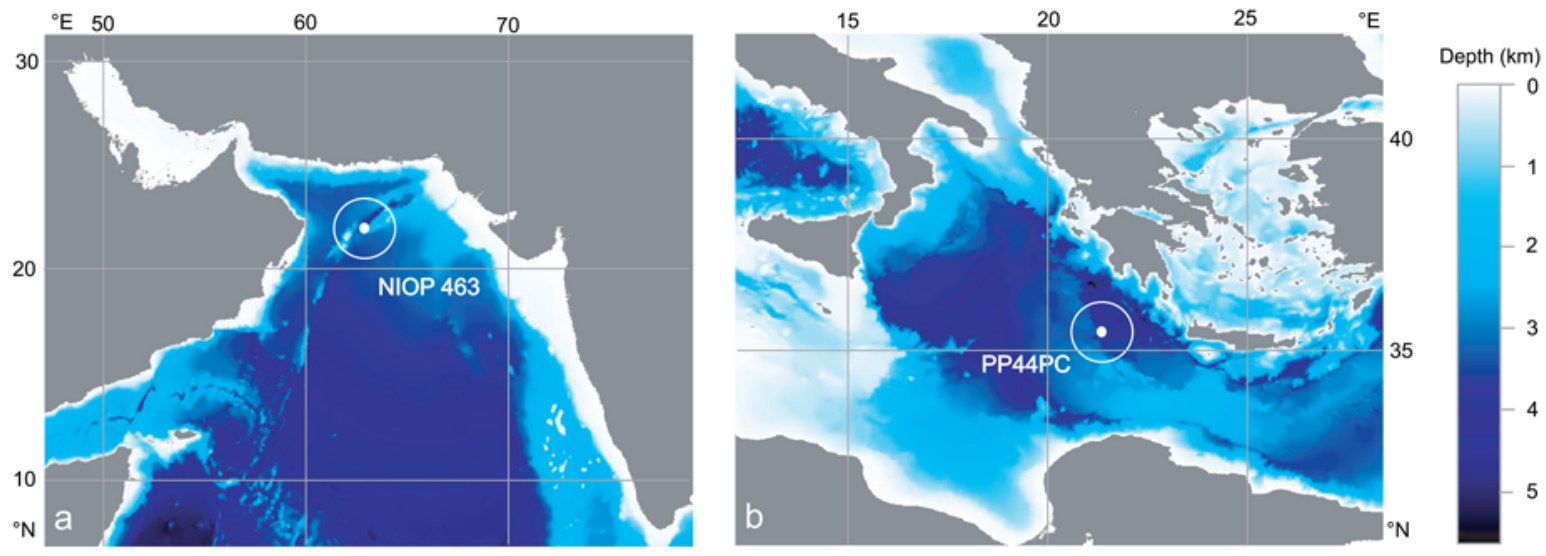

Figure 1. Coring locations of (a) NIOP 463 and (b) PP44PC.

the terrestrial environment, and hence terrestrial organic matter, is comparatively poor in bromine. Details of the relationship between $\mathrm{Br}$ and marine organic matter are still debated [see Mayer et al., 2007, and references therein] and will form the subject of further investigation. Here we investigate the potential of XRF $\mathrm{Br}$ counts/s as an estimate for MOC.

[3] We show that a correlation exists between XRF $\mathrm{Br}$ counts/s and sedimentary MOC in two sediment cores from contrasting marine environments. Alongside the XRF scanning data of the two cores, we performed conventional discrete sample analyses for TOC, water content, partitioning between organic $\mathrm{Br}\left(\mathrm{Br}_{\text {org }}\right)$ and salt $\mathrm{Br}\left(\mathrm{Br}_{\text {salt }}\right)$, and $\mathrm{Br} / \mathrm{Cl}$ ratios in the $\mathrm{Br}_{\text {salt }}$ component. The results allow us to estimate core-specific functions relating XRF bromine counts to MOC. In doing so, we extend the potential of XRF scanning as a fast, efficient method to establish sedimentary composition beyond the information yielded by elemental counts alone.

\section{Material and Methods}

[4] XRF core-scanning measurements were obtained directly at the split core surface of the archive half of each core, using the Avaatech XRF core scanner at the Netherlands Institute for Sea Research (NIOZ). The split core surface was covered with $4 \mu \mathrm{m}$ thickness SPEXCerti Prep Ultralene1 foil to avoid contamination of the XRF measurement unit and desiccation of the sediment. A Pd filter was placed in front of the incoming X-ray beam and measurements were taken at $1 \mathrm{~cm}$ resolution with a slit size of $1 \times$ $1.5 \mathrm{~cm}$, generator setting of $30 \mathrm{kV}$ and a sampling time of $30 \mathrm{~s}$. Further technical and practical details about the XRF core scanner are described by Richter et al. [2006]. While Tjallingii et al. [2007] showed that measurement of light elements can be affected (due to their limited response depth) by the development of a water film on the core surface, the atomic weight of bromine (80) ensures that it is not affected by these problems.

[5] Piston core NIOP $463\left(22^{\circ} 32.9^{\prime} \mathrm{N}, 064^{\circ} 02.8^{\prime} \mathrm{E}\right.$, 920 mbss) was collected at the base of the modern Oxygen Minimum Zone (OMZ) on Murray Ridge, Arabian Sea (Figure 1a). The sediments show organic carbon variations of between one and six $\mathrm{wt} \%$ TOC, related to changing OMZ intensity on orbital timescales [Reichart et al., 1998]. Pore water salinity is assumed to remain constant at the bottom water value of $38 \%$ throughout the core. Piston Core PP44PC Section $8\left(35^{\circ} 14.2^{\prime} \mathrm{N}, 21^{\circ} 29.8^{\prime} \mathrm{E}\right.$, $3378 \mathrm{mbss}$ ) was recovered from the Urania basin in the Eastern Mediterranean (Figure 1b). The basin is filled with a brine of $165 \%$ salinity, and dissolved $\mathrm{Br}$ is elevated to $0.315 \%$. However, the seawater $\mathrm{Br} / \mathrm{Cl}$ mass ratio of 0.0034 is maintained. Brine and pore waters are entirely anoxic, and the core section contains a well preserved example of the TOC-rich Holocene Sapropel S1.

[6] A series of discrete samples (1 cm stratigraphic thickness) was taken at $10 \mathrm{~cm}$ resolution from the working half of each section of NIOP 463, and at $1 \mathrm{~cm}$ resolution in the working half of PP44PC Section 8 . Water content was estimated by weight loss on freeze drying. Organic carbon and total nitrogen contents were measured with a CNS analyzer (Fisons NA 1500). Carbonate was extracted prior to CNS analysis by mechanical shaking with $1 \mathrm{M} \mathrm{HCl}$ for $12 \mathrm{~h}$, and rinsing with deionized water to remove $\mathrm{CaCl}_{2}$. This sequence 
was repeated with a $4 \mathrm{~h} \mathrm{HCl}$ shake to guarantee dolomite removal, after which the samples were again rinsed and finally oven dried. Replicate analyses of samples and comparison with international (Atropine, Acetanilide) and in-house (F-TURB and MM-91) standards were used to establish analytical precision and accuracy, which were both better than 3\%. In addition, we performed a sequential extraction on limited series of dried subsamples representing the full range of XRF Br counts, organic carbon and water content from each core. Assuming all $\mathrm{Br}$, in both cores, to be partitioned between organic carbon and salt fractions [Mayer et al., 1981], we rinsed the samples first with deionized water (to extract $\mathrm{Br}_{\text {salt }}$ ) and subsequently with hydrogen peroxide in an $80^{\circ} \mathrm{C}$ water bath (to extract $\mathrm{Br}_{\text {org }}$ ). Repeat rinses confirmed complete removal of extractable $\mathrm{Br}$ during the two steps. The deionized water rinses were subsequently analyzed using an Ion Chromatograph to calculate $\mathrm{Br} / \mathrm{Cl}$ ratios. These were always within $5 \%$ of the seawater value, indicating negligible removal of $\mathrm{Br}_{\text {org }}$ during pore water rinsing. Both deionized water and hydrogen peroxide rinses were analyzed by ICP-MS (precision $<1 \%$ ) for determination of extracted $\mathrm{Br}$.

\section{Results}

[7] Comparison of discrete sample TOC measurements with high-resolution XRF Br counts/s shows that the two parameters covary in both cores (Figures $2 \mathrm{a}$ and $2 \mathrm{~b}$ ). Maxima in organic carbon are consistently reproduced in the bromine data series. However, in the intervals $600-800 \mathrm{~cm}$ and $1100-1200 \mathrm{~cm}$ in NIOP 463 and the "early Sapropel S1" interval in PP44PC, the amplitude of individual bromine peaks is lower than predicted by the corresponding TOC peaks (note that the TOC peak in NIOP 463 around $420 \mathrm{~cm}$ is not reproduced due to missing XRF data).

\subsection{Influence of Terrestrial Organic Matter}

[8] To explain the mismatch between XRF $\mathrm{Br}$ counts/s and TOC in these intervals, a comparison was made with down core variations in $\delta^{13} \mathrm{C}_{\mathrm{TOC}}$ and the $\delta^{13} \mathrm{C}_{\mathrm{TOC}}$-estimated terrestrial organic carbon content of NIOP 463 (Figure 2a), assuming end-members of -20 (marine) and -26 (terrestrial) [Fontugne and Duplessy, 1986]. Terrestrial organic carbon content records maxima in the mismatched intervals, most clearly in the last interglacial period
(Marine Isotope Stage 5), which was characterized by strong Indian summer monsoon intensity [e.g., Emeis et al., 1995] and hence possible increased Indus river discharge. Therefore, we conclude that the mismatch between XRF Br counts/s and TOC in the intervals of heavily depleted $\delta^{13} \mathrm{C}_{\mathrm{TOC}}$ values is caused by the addition of low- $\mathrm{Br}$ terrestrial organic carbon.

[9] Subsequently, a (semi) quantitative estimate of MOC can be achieved for NIOP 463 by performing a regression analysis between the TOC values of the samples least affected by terrestrial contribution (i.e., $\delta^{13} \mathrm{C}_{\mathrm{TOC}}<-20$ ) and their respective XRF $\mathrm{Br}$ counts/s (Figure $2 \mathrm{c}$ ). The resulting $\mathrm{Br} / \mathrm{TOC}$ correlation coefficient of $0.89(\mathrm{n}=18)$ (Figure 2c) is higher than that for the entire sample set $(0.50, \mathrm{n}=$ 144) and effectively represents $\mathrm{Br} / \mathrm{MOC}$. Both correlations are significant at the $99 \%$ confidence level.

[10] Carbon isotope data was not available for $\mathrm{PP} 44 \mathrm{PC}$, and its $\mathrm{Br} / \mathrm{TOC}$ correlation is therefore presented without correction for terrestrial organic matter (Figure 2c). The low $\mathrm{Br} / \mathrm{TOC}$ of early Sapropel S1 suggests, however, that the input of terrestrial organic carbon was relatively high at this time. This conclusion is supported by a higher TOC: $\mathrm{N}_{\text {total }}$ ratio of this interval (13.8) relative to the later stage of S1 (13.0).

\subsection{Influence of Brine Salt}

[11] The $\mathrm{Br} / \mathrm{TOC}$ gradient is clearly steeper in PP44PC than in NIOP 463 and has a higher intercept at zero TOC (Figure 2c). Our sequential extraction results show that the brine core PP44PC has a $\mathrm{Br}_{\text {salt }}: \mathrm{Br}_{\text {org }}$ ratio far higher than that of NIOP 463 (Figure 3a). Assuming the larger $\mathrm{Br}_{\text {salt }}$ component of PP44PC to be responsible for the different intercepts, a salt correction was performed on the XRF Br counts of both cores. For this purpose all $\mathrm{Br}$ XRF counts were first normalized to water content, and plotted against TOC (Figure 3b). For NIOP 463, again only those samples with a minimum terrestrial organic matter contribution were used. The number of $\mathrm{Br}_{\text {salt }}$ counts/s per wt $\%$ water was subsequently derived from the intercept at zero TOC (Figure 3b). Using this relationship and the water content of each sample, the $\mathrm{Br}_{\text {org }}$ component (or $\mathrm{Br}_{\text {salt }}$ corrected XRF Br counts) can be calculated (Figure $3 \mathrm{c}$ ). The resulting $\mathrm{Br}_{\text {org }}$ :TOC regression of NIOP 463 passes through the origin. The regression for PP44PC, if samples from the early sapropel interval are excluded, shows a nearly 

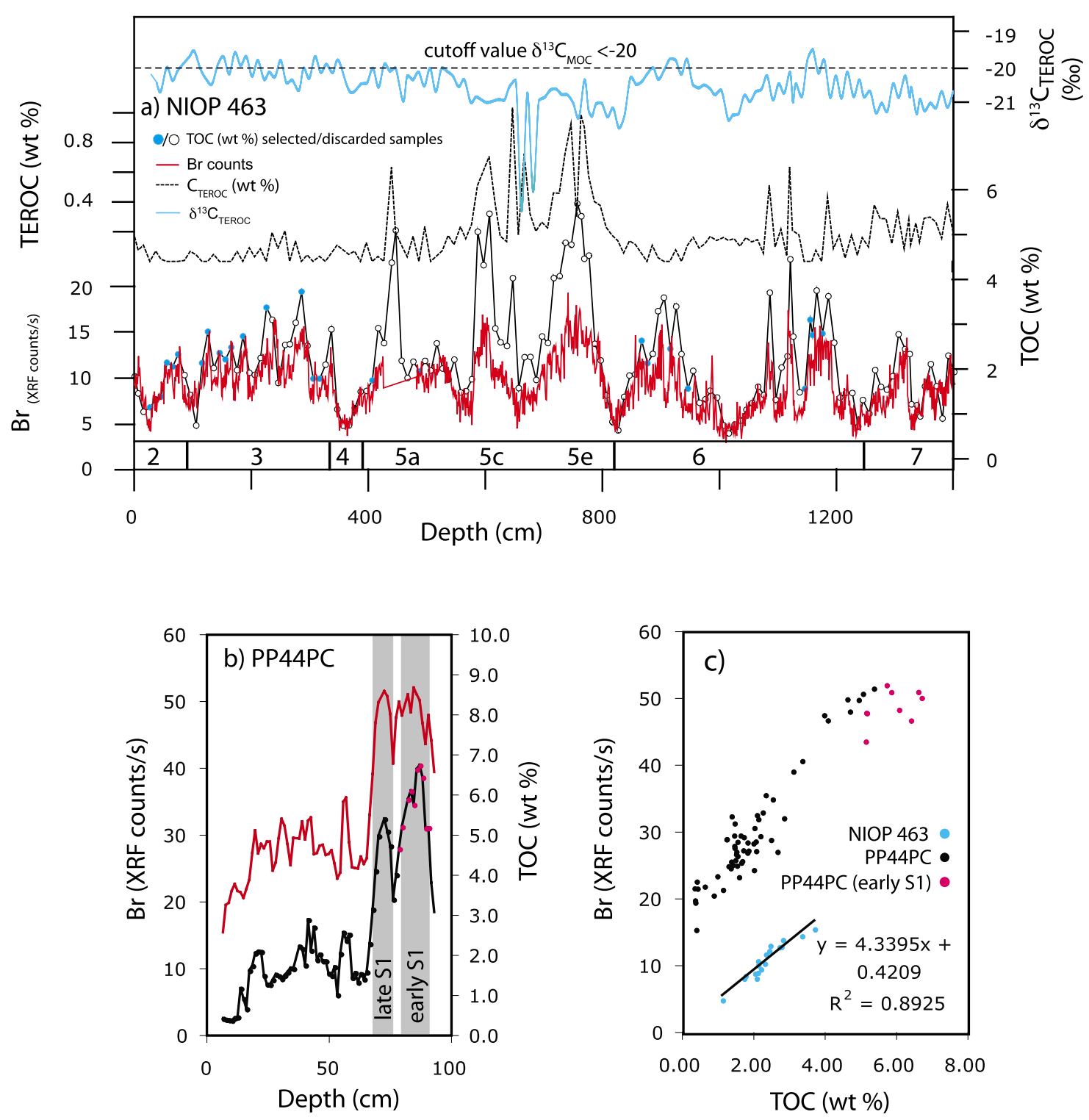

Figure 2. (a) Arabian Sea core NIOP 463. Depth profiles of $\delta^{13} \mathrm{C}_{\mathrm{TOC}}$, and the estimated terrestrial organic carbon (TEROC) content based on $\delta^{13} \mathrm{C}_{\mathrm{TOC}}$ (using TEROC $=\mathrm{TOC} *\left[\left(\delta^{13} \mathrm{C}_{\mathrm{MOC}}-\delta^{13} \mathrm{C}_{\mathrm{TOC}}\right) /\left(\delta^{13} \mathrm{C}_{\mathrm{TOC}}-\delta^{13} \mathrm{C}_{\mathrm{TOC}}\right)\right]$, endmembers $\delta^{13} \mathrm{C}_{\mathrm{MOC}}=-20$, and $\delta^{13} \mathrm{C}_{\mathrm{TEROC}}=-26$ [e.g., Fontugne and Duplessy, 1986]). Below are depth profiles of TOC (\%) and XRF Br total raw counts. Open symbols represent samples with $\delta^{13} \mathrm{C}_{\mathrm{TOC}}<-20$, which have been removed from subsequent regression. Numbers in the bar at the bottom indicate marine isotope stages according to the age model for NIOP 463 from Sinnighe Damste et al. [2002]. (b) Depth profiles of TOC (\%) and XRF Br counts/s for Mediterranean brine core PP44PC $\left(\delta^{13} \mathrm{C}\right.$ data not available). (c) Scatterplots of XRF $\mathrm{Br}$ counts/s versus total organic carbon content for the two cores. NIOP 463 data were selected on the basis of $\delta^{13} \mathrm{C}$ of organic carbon, excluding samples with a potential contribution of terrestrial organic matter.

identical gradient to that of NIOP 463 and also passes through the origin (Figure $3 \mathrm{c}$ ).

\section{Discussion and Conclusions}

[12] The common gradient of the two cores after salt correction implies that no post-depositional sorption of $\mathrm{Br}$ to organic matter occurs in the brine, a conclusion also drawn by Ten Haven et al. [1988] from another Mediterranean brine core. Therefore, the $\mathrm{Br} / \mathrm{MOC}$ ratio observed in our two cores is apparently fixed in the water column, and thus must be related to the initial association of $\mathrm{Br}$ with marine organic matter. Ambient salinity at the time of $\mathrm{Br}$ association may play a role; indeed, the lack of $\mathrm{Br}$ in terrestrial organic matter is caused by the 

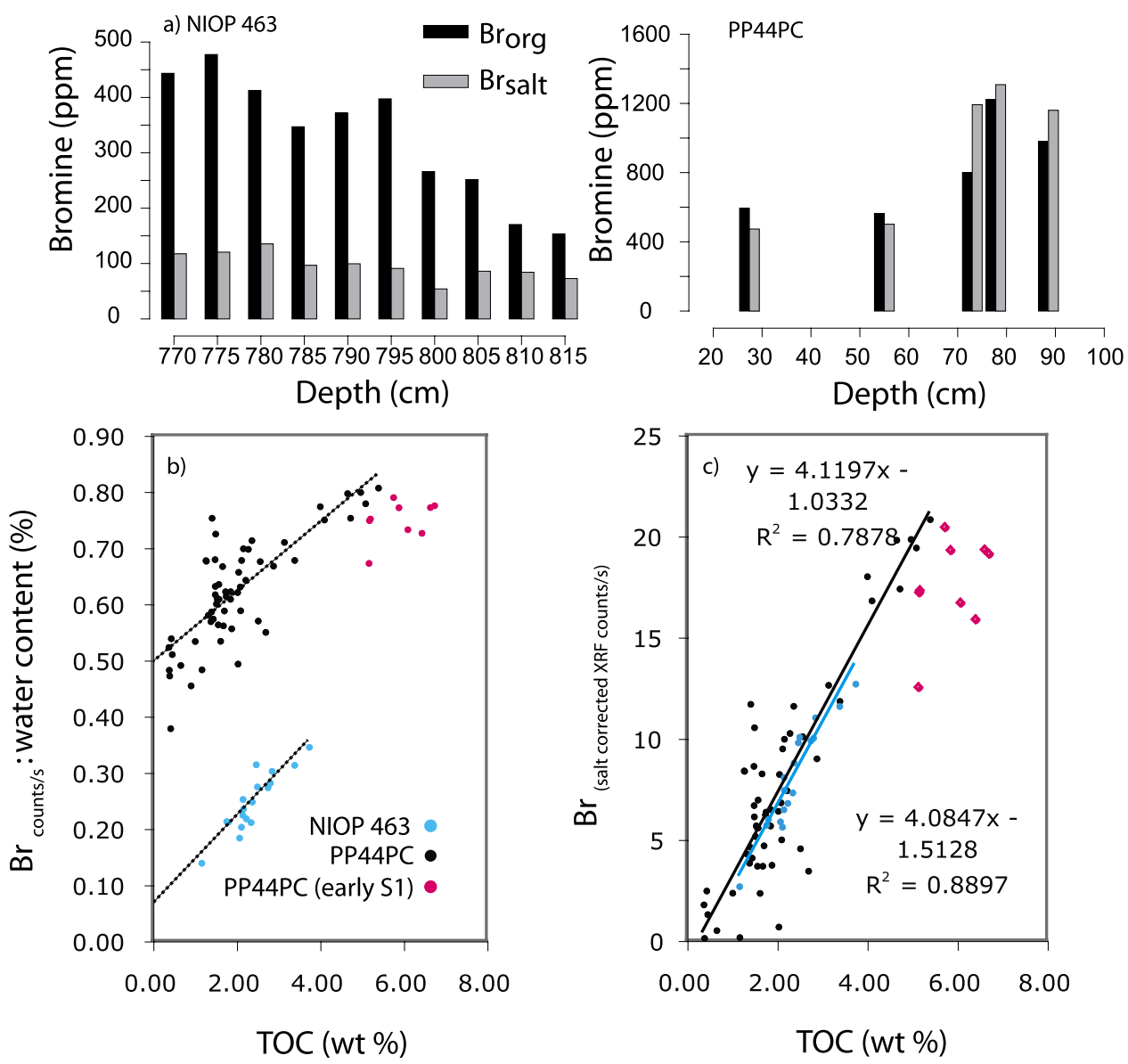

Figure 3. (a) Results of the sequential extraction, showing the partitioning of organic and salt bromine in Arabian Sea core NIOP 463 and Mediterranean brine core PP44PC (data in ppm water-free sediment; note different $y$ axis scales). (b) XRF Br counts/water content (\%) plotted versus TOC. Intercept with $y$ axis gives a measure of XRF $\mathrm{Br}$ counts/s per 1\% water content for NIOP 463 and PP44PC. (c) Salt contribution corrected XRF Br counts/s plotted versus TOC.

low salinity of the terrestrial environment. Therefore, the similar surface water salinities of the Eastern Mediterranean and Arabian Sea could explain the common gradient. By extension, the drop in Mediterranean surface water salinity [Van der Meer et al., 2007] during the onset of sapropel formation might be evoked as an alternative explanation for the low Br/TOC of early Sapropel S1. However, further study is required to improve our understanding of the potential paleosalinity information stored in sedimentary $\mathrm{Br} / \mathrm{MOC}$ ratios.

[13] Although our two cores yield a common function for estimating MOC from XRF $\mathrm{Br}$ counts/s, such data remain sensitive to the settings of the XRF apparatus. Thus, when applying the method it is necessary to analyze a short series of discrete samples for TOC and $\delta^{13} \mathrm{C}_{\mathrm{TOC}}$, to establish a quantitative $\mathrm{Br} / \mathrm{MOC}$ calibration for the core in question. Salt correction of the XRF data, requiring a full series of water content measurements, is not a prerequisite for the calculation of MOC from XRF $\mathrm{Br}$ counts/s, since a linear empirical relationship exists in salt-uncorrected data (Figure 2c). However, significant salt contribution affects the gradient of this relationship.

[14] The advantages of the XRF scanning approach are clear: data is acquired quickly, and at high resolution, allowing the identification of shorttimescale changes in sedimentary (paleoenvironmental) archives. MicroXRF scanning [e.g., Böning et al., 2007] potentially allows the determination of changes in sedimentary MOC on the submillimeter scale, facilitating the investigation of sedimentary microfabrics and interannual accumulation variability. In addition, recently developed handheld XRF scanning devices [e.g., Moore, 2006] offer the possibility to analyze the organic carbon content of land-based marine deposits in geologic sections 
in the field. Since the standard procedure of XRF scanning involves measurements of most other major elements, $\mathrm{Al}$ or $\mathrm{Ti}$ counts can be used to normalize $\mathrm{Br}$ in order to estimate the relative input of sedimentary components.

[15] To conclude, Br XRF scanning counts can be used as a quick and nondestructive, high-resolution, semiquantitative estimate of sedimentary TOC. Deviations from the overall linear relationship between $\mathrm{Br}$ and TOC can be explained by the influence of low-Br terrestrial organic matter, and after removal of these samples a strong linear relationship, representing $\mathrm{Br} / \mathrm{MOC}$, is observed. Records from two contrasting regions display, after correction for the contribution from dissolved $\mathrm{Br}$, common $\mathrm{Br} / \mathrm{MOC}$ regression slopes.

\section{Acknowledgments}

[16] We are grateful for technical and scientific help by Thomas Richter, Helen de Waard, Rineke Giles, Aad Vaars, Bertil van Os, and Erik van Vilsteren. Helpful comments by Phillip Böning and an anonymous reviewer are acknowledged. This work was supported by the Netherlands Organization for Scientific Research (NWO).

\section{References}

Böning, P., E. Bard, and J. Rose (2007), Toward direct, micron-scale XRF elemental maps and quantitative profiles of wet marine sediments, Geochem. Geophys. Geosyst., 8, Q05004, doi:10.1029/2006GC001480.

Emeis, K.-C., D. M. Anderson, H. Doose, D. Kroon, and D. Shulz-Bull (1995), Sea-surface temperatures and the history of monsoon upwelling in the northwest Arabian Sea during the last 500000 years, Quat. Res., 43(3), 355361, doi:10.1006/qres.1995.1041.

Fontugne, M. R., and J. C. Duplessy (1986), Variations of the monsoon regime during the upper Quaternary: Evidence from carbon isotopic record of organic matter in north Indian Ocean sediment cores, Palaeogeogr. Palaeoclimatol. Palaeoecol., 56, 69-88, doi:10.1016/0031-0182(86)90108-2.

Hopmans, E. C., J. W. H. Weijers, E. Schefuß, L. Herfort, J. S. Sinnighe Damste, and S. Schouten (2004), A novel proxy for terrestrial organic matter in sediments based on branched and isoprenoid teraether lipids, Earth Planet. Sci. Lett., 224(12), 107-116, doi:10.1016/j.eps1.2004.05.012.

Mayer, L. M., S. A. Macko, W. H. Mook, and S. M. Murray (1981), The distribution of bromine on coastal sediments and its use as a source indicator for organic matter, Org. Geochem., 3, 37-42, doi:10.1016/0146-6380 (81)90011-5.

Mayer, L. M., L. L. Schick, M. A. Allison, K. C. Ruttenberg, and S. J. Bentley (2007), Marine vs. terrigenous matter in Louisiana coastal sediments: The uses of bromine:organic carbon ratios, Mar. Chem., 107, 244-254, doi:10.1016/ j.marchem.2007.07.007.

Moore, P. (2006), Portable XRF, Min. Mag, 195(6), 28-29.

Reichart, G. J., L. J. Lourens, and W. J. Zachariasse (1998), Temporal variability in the northern Arabian Sea Oxygen Minimum Zone (OMZ) during the last 225000 years, Paleoceanography, 13(6), 607-621, doi:10.1029/98PA02203.

Richter, T. O., S. van der Gaast, B. Koster, A. Vaars, R. Gieles, H. C. de Stigter, H. de Haas, and T. C. E. van Weering (2006), The Avaatech XRF Core Scanner: Technical description and applications to NE Atlantic sediments, in New Techniques in Sediment Core Analysis, edited by R. G. Rothwell, Geol. Soc. Spec. Publ., 267, 39-50.

Rohling, E. J. (1994), Review and new aspects concerning the formation of eastern Mediterranean sapropels, Mar. Geol., 122, 1-28, doi:10.1016/0025-3227(94)90202-X.

Rühlemann, C., P. J. Müller, and R. Schneider (1999), Organic carbon and carbonate as paleoproductivity proxies: Examples from high and low productivity areas of the tropical Atlantic, in Use of Proxies in Paleoceanography: Examples From the South Atlantic, edited by G. Fischer and G. Wefer, pp. 315-344, Springer, Berlin.

Schulz, H., U. von Rad, and H. Erlenkeuser (1998), Correlation between Arabian Sea and Greenland climate oscillations of the past 110,000 years, Nature, 393(6680), 54-57.

Sinnighe Damste, J. S., W. I. C. Rijpstra, and G.-J. Reichart (2002), The influence of oxic degradation on the sedimentary biomarker record II. Evidence from Arabian Sea sediments, Geochim. Cosmochim. Acta, 66, 2737-2754.

Ten Haven, H. L., J. W. de Leeuw, P. A. Schenck, and G. T. Klaver (1988), Geochemistry of Mediterranean sediments: Bromine/organic carbon and uranium/organic carbon ratios as indicators for different sources of input and post-depositional oxidation, respectively, Org. Geochem., 13(1-3), 255-261, doi:10.1016/0146-6380(88)90044-7.

Thomson, J., I. W. Croudace, and A. Rothwell (2006), A geochemical application of the ITRAX scanner to a sediment core containing eastern Mediterranean sapropel units, in New Techniques in Sediment Core Analysis, edited by R. G. Rothwell, Geol. Soc. Spec. Publ., 267, 65-77.

Tjallingii, R., U. Röhl, M. Kölling, and T. Bickert (2007), Influence of the water content on X-ray fluorescence corescanning measurements in soft marine sediments, Geochem. Geophys. Geosyst., 8, Q02004, doi:10.1029/2006GC001393.

Van der Meer, M. T. J., M. Baas, W. I. C. Rijpstra, G. Marino, E. J. Rohling, J. S. Sinnighe Damste, and S. Schouten (2007), Hydrogen isotopic compositions of long-chain alkenones record freshwater flooding of the Eastern Mediterranean at the onset of sapropel deposition, Earth Planet. Sci. Lett., 262, 594-600, doi:10.1016/j.eps1.2007.08.014. 